\title{
Cultural Symbiosis: Chu Culture and Course Teaching of Interface Design- A Case Study on A Chinese Bestiary
}

\author{
Zhijuan Zhu, Mengze Fan, Chenyue Sun and Ren Long ${ }^{+}$ \\ School of Mechanical Science and Engineering, Huazhong University of Science and Technology, Wuhan, \\ China, 430074
}

\begin{abstract}
Chu culture's connotation is broad and profound, however, the content of ancient books is difficult to be loved by people in the modern context. In the course of interface design, the study of Chu culture and the teaching of interface design were combined based on the theory of cultural symbiosis. After analyzing the interface design of traditional culture APPs, design disciplines of these APPs including sense of interest, usability and consistency were proposed. In the end, the APP named A Chinese Bestiary was taken as a design case study, and interface design of the APP was presented. The education model of the cultural symbiosis, would be extended in other related design courses.
\end{abstract}

Keywords: symbiosis, Chu culture, interface design, course teaching, A Chinese Bestiary.

\section{Introduction}

As the main part of Chinese civilization in the south of China, Chu culture's connotation is broad and profound. [1] However, traditional culture, especially the content of ancient books, is facing the difficulty of not being loved by people in the modern background. These ancient books will be farther and farther away from people's lives, which is unfavourable to cultural heritage. In the era of the prevalence of mobile Internet, people's reading habits gradually change from the paper media to digital media. An important issue that how to transmit ancient culture in the contemporary society arouses widely concern.

\subsection{Course of interface design}

With the rapid development of computer and network technology, digital media education is bound to be an important task for colleges and universities. The course of interface design is a compulsory course for college students majoring in design. By learning the course, students should understand hardware and software interface theories and methods, explore the new interactive technology, be familiar with the design process and the features of user interface (UI). In addition, they should complete UI design works by using the Adobe Photoshop, Adobe Illustrator and other design software to complete the visual performance.

\subsection{Cultural symbiosis}

The concept of "symbiosis" derives from Anton de Bary(1879), which refers to the life of different species living together, the use of each other's characteristics and their own characteristics to live together with each other. Symbiosis is a common phenomenon in nature and human society.

Symbiotic theory, as an important theory of biology, is the development of Darwin's theory of evolution. The theory of evolution is to emphasis the competition and antagonism between organisms, while the theory of symbiosis is to highlight the dependence and promotion of living things. As a kind of methodology to describe the relationship between species, the theory of symbiosis can be used in other fields. With the

\footnotetext{
+ Corresponding author. Tel.: +86-15827083330; fax: +86-27-87556904

E-mail address:longren@hust.edu.cn.
} 
continuous development of the concept of symbiosis, it was applied to anthropology, sociology, economics, management science, architecture, education and political science to solve social problems, thus forming a rich connotation of symbiotic theory.[2]

In the theory of cultural symbiosis, it is generally understood as a symbiotic relationship between many cultures in different areas. [3] In this paper, the cultural symbiosis, which is different from the multicultural symbiosis, refers to the symbiosis of traditional culture and modern culture. The purpose of this paper is to discuss the inheritance of traditional culture in the modern mobile Internet era and how to integrate the traditional culture into the interface design course.

\subsection{Symbiosis of Chu culture and course teaching of Interface Design}

At present, with the increasingly fast pace of life, few people has a quiet study of ancient books. In the teaching process of design course, the symbiosis between traditional culture and modern culture will promote the spread of traditional culture in modern society, which is worthy of exploration. The combination of the research of Chu culture and the teaching of interface design is also worth experimenting.

\section{Method}

\subsection{Course requirements}

Based on the theory of cultural symbiosis, the study of Chu culture and the course teaching of interface design were combined in the project teaching of interface design. According to the inheritance, improvement and innovation of the Chu culture, the research on the UI design was carried out, and the interface design of the APP was completed. During the course teaching process, students were required to understand the core content of Chu culture, consider people's cognitive habits, and promote new vitality of Chu culture by using modern design techniques.

\subsection{A Chinese Bestiary}

The most important value of A Chinese Bestiary is that it saves a lot of myths and legends. As ancient cultural classics, Book of Songs and $\mathrm{Chu} \mathrm{Ci}$ are the two representatives of the pre Qin literature, and the mythology cited in the two books are mainly derived from the A Chinese Bestiary. It can be believed that A Chinese Bestiary is one of the important representative of Chu culture.

However, these myths and legends are not familiar with the general public in recent society. As an ancient book, A Chinese Bestiary is difficult to understand for modern people. A Taiwan cartoonist named Zhizhong Cai has described the books as follows, "90\% of the people know it, but $90 \%$ people know they don't know it." That means, most Chinese have heard of the book, but they also know that they do not know the meaning and content of the book actually.

In the exploration of course teaching, the Chu culture and interface design teaching were combined together based on cultural symbiosis. A Chinese Bestiary will be taken as an example, and the corresponding APP UI design will be generated to promote the dissemination of the Chu culture.

\subsection{Research Process}

During the course teaching, the research process of APP interface design for A Chinese Bestiary is shown in Fig. 1 which followed the typical UI design process and adjusted to fit for the design theme.

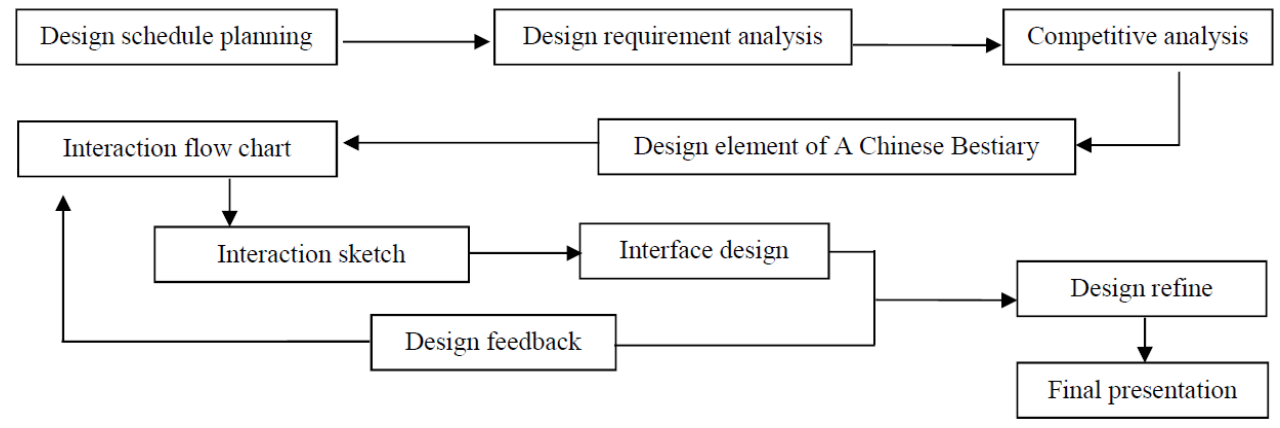

Fig. 1: Research process. 


\subsection{Design requirements}

In the existing APPs with the same theme, illustration is not attractive, and most of these APPs are full of a large number of text description, which is only a simple transplant of the ancient book. In the project teaching mode of the course, we aims to design an APP based on A Chinese Bestiary, so that people who want to know A Chinese Bestiary will not be blocked by the cumbersome ancient texts and uninteresting illustrations.

\subsubsection{Target users}

The target users of the APP are young group who are 15 35 years old and want to know Chu culture.

\subsubsection{Users' role cards}

Energetic girl A: A is an energetic university student with cheerful personality, and interested in ancient books. However, she has no plenty of time to learn A Chinese Bestiary because of the heavy schoolwork. She hopes that there is an APP based on A Chinese Bestiary for her to use every spare minute.

Sunshine boy B: B believes that the ancient literature are very cool and interesting, and he would like to have an APP which can provide him a number of simplified classical literature and illustrations based on ancient books.

\subsection{Competitive analysis}

The same type of APP product interface were collected in the APP store, such as Forbidden City, Tea, Wood Joints, Daily Forbidden City, etc. After analyzing the UI design, the following design principles were found in the traditional culture of APP design.

- Sense of interest: Intuitive graphics are more attractive than the stacked texts; novel and interesting human-computer interaction mode can make the APP more interesting; emotional design can help to increase the sense of interest.

- Usability: The interaction should be the same as the mental model of common human, which makes the APP easy to use.

- Consistency: Pictures, charts should be consistent with the traditional classical style; all pages and elements should be consistent in style.

In summary, the UI of the APP should be simple, elegant, concise, to fit the style of ancient books and make users more easy to accept.

\subsection{Design elements analysis of A Chinese Bestiary}

In the ancient book of A Chinese Bestiary, there are many strange creatures which are far away with people's real lives. The consistency of styles for all creatures should be emphasized in the design elements research. These elements include logo design and illustration design. Design sketch is based on these design elements. Fig. 2 shows part of these elements. The current popular flat design style were utilized, to fit with the preferences of the target users.

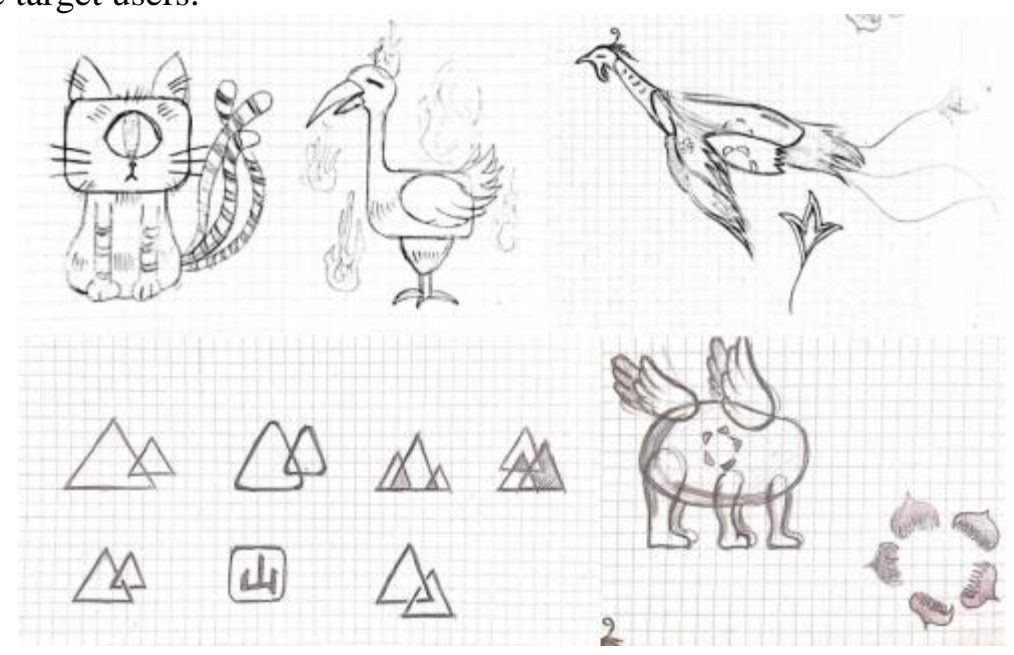

Fig. 2: Part of design elements of A Chinese Bestiary 


\section{Result and discussion}

\section{1. logo design}

The flat design style were adopted in the logo design (see Fig.3).

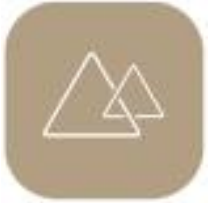

Fig. 3: Logo design of the APP

\subsection{Illustration design}

Creatures of A Chinese Bestiary (See Fig.4) were illustrated instead of plenty of boring descriptive texts, which made the APP more interesting and appealing to users than existing APPs. As shown in Fig. 5, a map marked location of these creatures instead of common text catalogue in the APP made it more intuitive. All pages and elements were full of Chinese traditional sense.
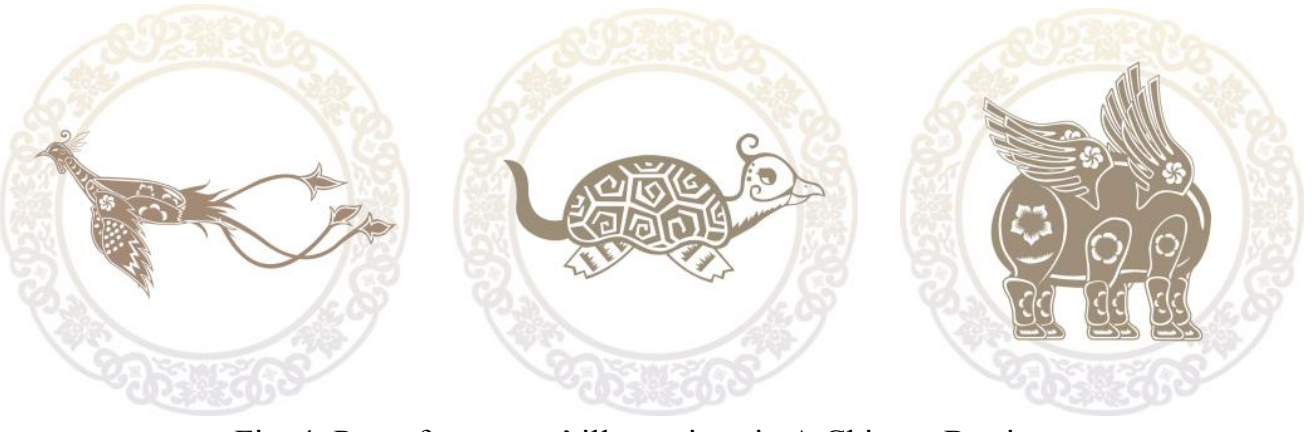

Fig. 4: Part of creatures' illustrations in A Chinese Bestiary.

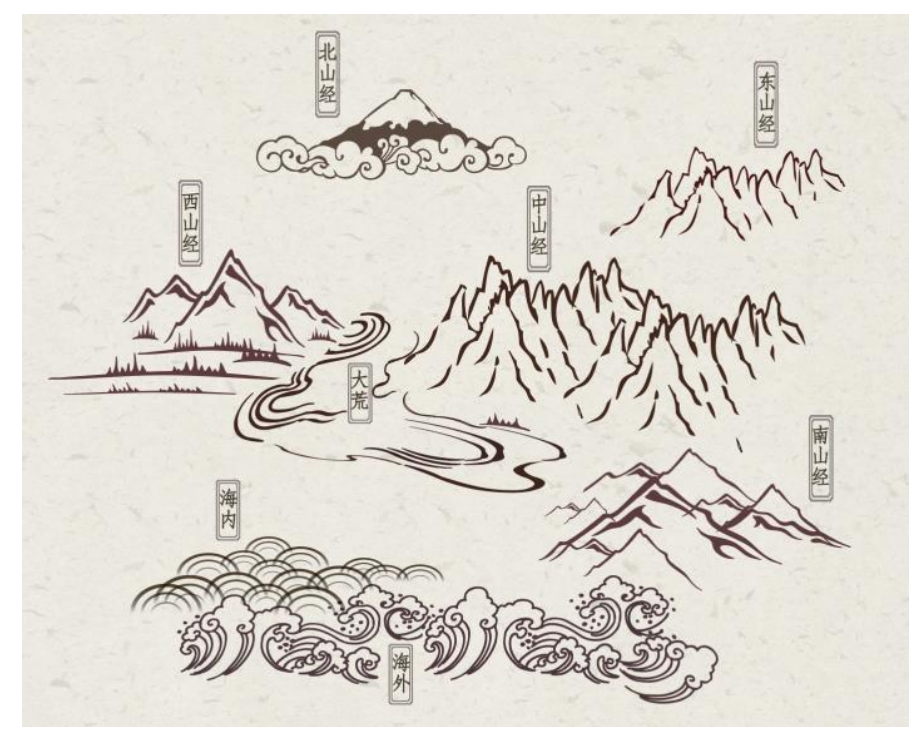

Fig. 5: A map marked location of the creatures in A Chinese Bestiary

\subsection{Interface design}

All unnecessary texts were hided in the UI design, so all pages are concise and clear. The page turning style is sliding instead of clicking, which is accustomed for users to use. (See Fig. 6) 


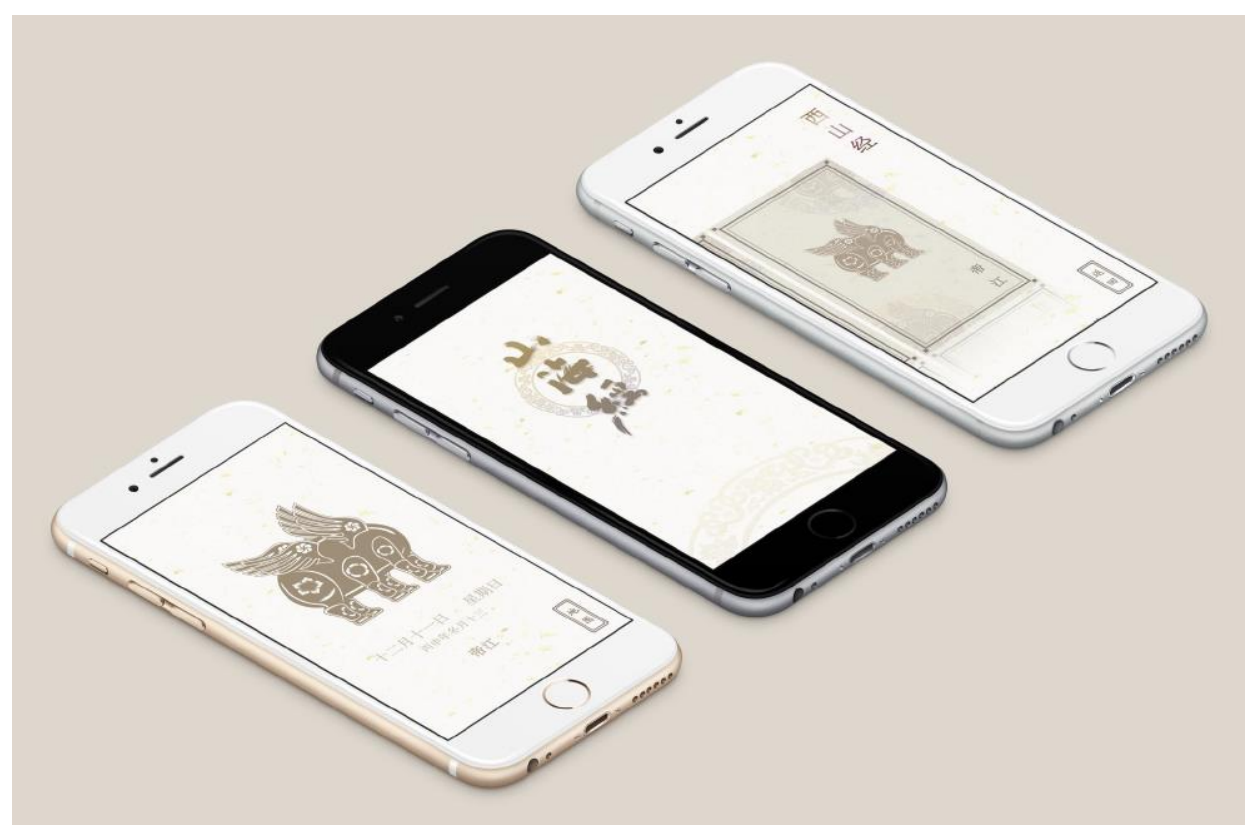

Fig. 6: Final interface design.

\subsection{UI Design feedback}

Six target users were invited into the interview of the APP, their feedbacks were as follows.

User A: This is the best I have seen to bring people into the world of traditional Chinese culture APP! I

like it very much.

User B: Its style is very elegant and attractive to me.

User C: It is easy to use. The interface is clear and there is no obstacle even if it is the first time for me to use because it is fit with people's mental model.

User D: The interface is very beautiful, but I hope you can use more colors.

User E: I hope this APP can include not only the content of A Chinese Bestiary, but also some extended content.

User F: The use of the map is very interesting.

\subsection{Course feedback}

Through the interface design course, students learned related knowledge of interface design, understood related contents of A Chinese Bestiary, and have a deeper understanding of the Chu culture.

\section{Conclusions}

The symbiosis of Chu culture and the course teaching in interface design, made the Chu culture have new vitality and be transmitted better in the Internet plus era. During the process of course teaching, students not only had a better understanding of traditional culture, but also mastered the interface design process and methods to achieve good results. The kind of education mode of cultural symbiosis can be extended in other related design courses.

\section{Acknowledgements}

This work was financially supported by the Teaching Research Project of Hubei Province (No.2015056; No. 2016075) and CES-Kingfar Excellent Young Scholar Joint Research Funding (CES-KF-2016-05).

\section{References}

[1] X. Chen, R. Long, Z. Zhu, L. Chen. Application Research of Chu Culture Symbols Based on the Product Semantics. In: Proc. of 2016 International Conference on Computational Modeling, Simulation and Applied Mathematics. Bangkok, Thailand. 2016, pp. 423-427.

[2] G. Wilke, E. Portmann. Granular computing as a basis of human-data interaction: a cognitive cities use case. Granular Computing. 2016, 1(3): 181-197.

[3] G. Hofstede, B. Neuijen, D. D. Ohayv, et al. Measuring Organizational Cultures: A Qualitative and Quantitative Study across Twenty Cases. Administrative Science Quarterly. 1990, 35(2):286-316. 